\title{
General Observation of Photocatalytic Oxygen Reduction to Hydrogen Peroxide by Organic Semiconductor Thin Films and Colloidal Crystals
}

Maciej Gryszel, Mykhailo Sytnyk, Marie J akesova, Giuseppe Romanazzi, Roger Gabrielsson, Wolfgang Heiss and Eric Glowacki

The self-archived postprint version of this journal article is available at Linköping University Institutional Repository (DiVA):

http:/ / urn.kb.se/ resolve?urn=urn:nbn:se:liu:diva- 147927

N.B.: When citing this work, cite the original publication.

Gryszel, M., Sytnyk, M., J akesova, M., Romanazzi, G., Gabrielsson, R., Heiss, W., Glowacki, E., (2018), General Observation of Photocatalytic Oxygen Reduction to Hydrogen Peroxide by Organic

Semiconductor Thin Films and Colloidal Crystals, ACS Applied Materials and Interfaces, 10(16), 13253-13257. https:// doi.org/ 10.1021/ acsami.8b01295

Original publication available at:

https:// doi.org/ 10.1021/acsami.8b01295

Copyright: American Chemical Society

http:/ / pubs.acs.org/ 


\title{
General Observation of Photocatalytic Oxygen Reduction to Hydro- gen Peroxide by Organic Semiconductor Thin Films and Colloidal Crystals
}

\author{
Maciej Gryszel,§ Mykhailo Sytnyk, ${ }^{\S}$ Marie Jakešová,, Giuseppe Romanazzi, ${ }^{\S}$ Roger Gabrielsson, ${ }^{\S}$ Wolfgang Heiss, ${ }^{\#}$ and \\ Eric Daniel Głowacki*, \\ ${ }^{\S}$ Laboratory of Organic Electronics, Department of Science and Technology, Linköping University, Bredgatan 33, SE-60174, \\ Norrköping, Sweden \\ \#Materials for Electronics and Energy Technology (i-MEET), Friedrich-Alexander-Universität Erlangen-Nürnberg, \\ Martensstraße 7, 91058 Erlangen, Germany; Energie Campus Nürnberg (EnCN), Fürtherstraße 250, 90429 Nürnberg, \\ Germany \\ ${ }^{\nabla}$ Dipartimento di Ingegneria Civile Ambientale, del Territorio Edile e di Chimica (DICATECh) Politecnico di Bari, via \\ Orabona 4, 70125 Bari, Italy
}

Keywords: photochemistry, photocatalysis, hydrogen peroxide, organic semiconductors, oxygen reduction reaction, photoanodes

\begin{abstract}
Low-cost semiconductor photocatalysts offer unique possibilities for industrial chemical transformations and energy conversion applications. We report that a range of organic semiconductors are capable of efficient photocatalytic oxygen reduction to $\mathrm{H}_{2} \mathrm{O}_{2}$ in aqueous conditions. These semiconductors, in the form of thin films, support a 2electron/2-proton redox cycle involving photoreduction of dissolved $\mathrm{O}_{2}$ to $\mathrm{H}_{2} \mathrm{O}_{2}$, with the concurrent photooxidation of organic substrates: formate, oxalate, and phenol. Photochemical oxygen reduction is observed in a pH range from 2-12. In cases where valence band energy of the semiconductor is energetically high, autooxidation competes with oxidation of the donors, and thus turnover numbers are low. Materials with deeper valence band energies afford higher stability and also oxidation of $\mathrm{H}_{2} \mathrm{O}$ to $\mathrm{O}_{2}$. We found increased $\mathrm{H}_{2} \mathrm{O}_{2}$ evolution rate for surfactant-stabilized nanoparticles versus planar thin films. These results evidence that photochemical $\mathrm{O}_{2}$ reduction may be a widespread feature of organic semiconductors, and open potential avenues for organic semiconductors for catalytic applications.
\end{abstract}

Semiconductor-mediated photocatalytic redox reactions are a major focus of energy conversion and sustainability research, with photochemical production of hydrogen and fuels from $\mathrm{CO}_{2}$ reduction being two well-developed areas. ${ }^{1-3}$ An emerging concept for solar-to-fuel conversion is the photochemical generation of hydrogen peroxide, which is a high energy-density liquid fuel which can be used to drive single-compartment fuel cells. ${ }^{4-6}$ Photochemical generation of $\mathrm{H}_{2} \mathrm{O}_{2}$ from $\mathrm{O}_{2}$ and water is possible using carbon nitride derivatives, though catalytic stability of these systems has not been verified. ${ }^{5,7}$ Herein we propose that such catalytic transformations can be generally possible with common organic semiconductors. Organic semiconductors have only recently begun to receive more attention in photocatalysis, where hydrogen evolution ${ }^{8-11}$, primarily with cocatalysts, has been demonstrated. ${ }^{12-15}$ Interest in photochemical and photofaradaic reactions with organic semiconductors has arisen in the context of emerging bioelectronics devices, where potential

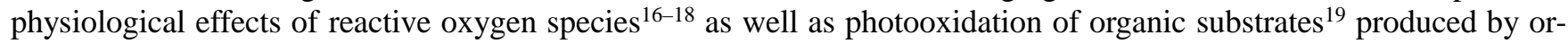
ganic semiconductors have been pointed out in several studies. We have recently reported that some organic semiconductors, namely acridones ${ }^{20}$ and coumarin derivatives, ${ }^{21}$ can be used as photocathodic materials which generate hydrogen peroxide. In parallel, we found that the n-type material perylene tetracarboxylicbisimide, is an electrocatalyst for oxygen reduction to hydrogen peroxide. ${ }^{22}$ These results of hydrogen peroxide production via oxygen reduction by organic semiconductor electrodes encouraged us to explore the possibilities of purely photocatalytic oxygen reduction to peroxide by organic semiconductors, with the simultaneous photooxidation of a sacrificial electron donor. As active materials we have chosen to evaluate three representative organic semiconductors with differing conductivity properties, namely ptype, n-type, and ambipolar: 1) the ambipolar organic semiconductor epindolidione (EPI), which has shown aqueous operational stability in the context of transistors ${ }^{23,24}$ and photocathodes; 2 ) perylene tetracarboxylicdiimide (PTCDI), ${ }^{25}$ 
with exclusively n-type conduction; and 3) poly(3-hexylthiophene), P3HT, with p-type conductivity and an established literature in organic devices. ${ }^{26,27}$ The molecular structures, with their respective optical band gaps and frontier orbital energy levels, are shown in Figure 1a. The evaluation of photochemical hydrogen peroxide evolution was performed by placing a sample of a thin-film of EPI, PTCDI, or P3HT, in a glass vial with aqueous electrolyte under $1 \mathrm{~atm}$ of $\mathrm{O}_{2}$ (Figure 1b). The aqueous electrolytes were $\mathrm{pH}$ 2, 7, and 12, made with $\mathrm{HCl}, \mathrm{Na}_{2} \mathrm{SO}_{4}$, and $\mathrm{NaOH}$, respectively.

a)

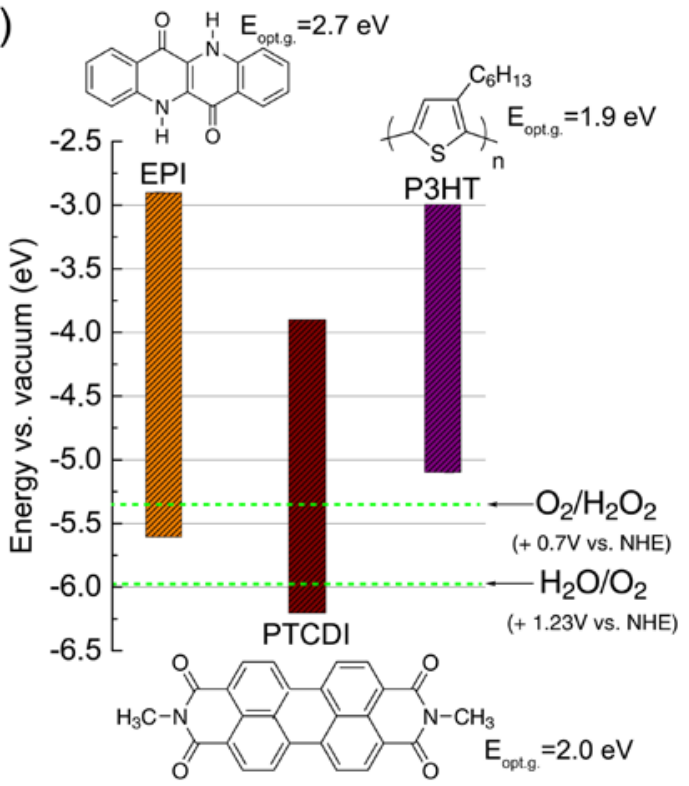

b)

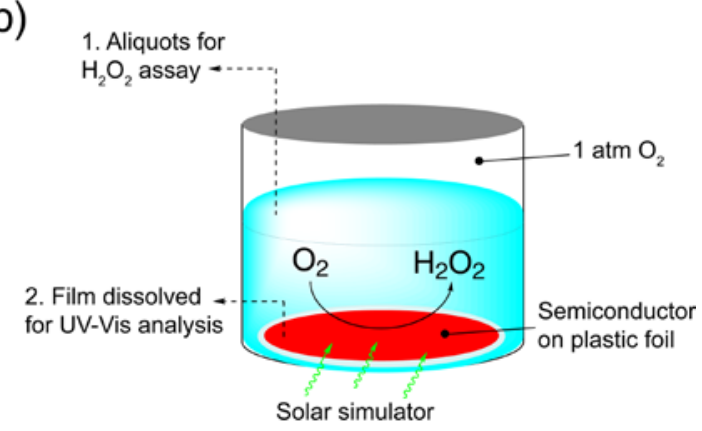

Figure 1. a) Molecular structures of epindolidione (EPI), $N, N$ '-dimethyl perylene tetracarboxylicdiimide (PTCDI), and poly(3hexylthiophene) (P3HT), on an energy diagram. Optical bandgaps are given for the respective solid-state materials, while the frontier orbital energy levels shown in the plot are estimations from electrochemical measurements. All three materials have LUMO levels capable of oxygen reduction to $\mathrm{H}_{2} \mathrm{O}_{2}$, while PTCDI has a HOMO level deep enough to oxidize water as well. Green dotted lines show where the respective potentials versus NHE correspond to the Fermi scale. b) Setup for evaluating photocatalytic oxygen reduction to $\mathrm{H}_{2} \mathrm{O}_{2}$.

The sacrificial donors $(10 \mathrm{mM})$ that were explored were formate, oxalate, and phenol, with "blank" signifying the electrolyte solution alone, i.e. the condition where $\mathrm{H}_{2} \mathrm{O}$, or the organic semiconductor layer itself, are the only potential electron donors. Vials were saturated with oxygen, closed, and then placed on a solar simulator setup equipped with cooling fans. Aliquots of solution were regularly sampled and $\mathrm{H}_{2} \mathrm{O}_{2}$ concentration was quantified using the tetramethylbenzidine/horseradish peroxidase assay. ${ }^{20,28}$ Table 1 shows the results of $\mathrm{H}_{2} \mathrm{O}_{2}$ concentration after 20h for all conditions. To understand the photochemical process in detail, calculation of turnover number (TON) is necessary. In this case, TON refers of the molar quantity of $\mathrm{H}_{2} \mathrm{O}_{2}$ evolved divided by the molar quantity of organic semiconductor that degrades over the same period. The amount of organic semiconductor which photochemically degrades is calculated from the absorbance spectrum of the material measured after dissolving the layer in solution and comparing with absorbance of a control sample which was not irradiated. Optical absorption of the dissolved material as opposed to direct optical measurements of the films was preferred to discount the contribution of any morphological/polymorphic changes which can occur and influence absorption and give spurious readings for amount of degraded material. The results for TON (Figure 2) allow one to distinguish two different regimes: where the TON is $\leq 1$, indicating that the semiconductor itself is the substrate in the photoreaction, and where TON is substantially greater, corresponding to true photocatalysis. Oxalate and phenol are the best sacrificial donors for photocatalysis in the case of EPI and PTCDI, where TONs in the 
range of 10-800 are possible. PTCDI is the only material with TON $>1$ in the "blank" case, indicating that PTCDI is capable of photocatalytically oxidizing water. This can be predicted based on the energy diagram in Figure 1 - only PTCDI is appropriate for water oxidation. The catalytic activity of PTCDI for $\mathrm{H}_{2} \mathrm{O}_{2}$ production from $\mathrm{O}_{2}$ and water is 2.7 $\mu \mathrm{g} \mathrm{H}_{2} \mathrm{O}_{2}$ / mg catalyst per hour at $\mathrm{pH} 7$, and $5 \mu \mathrm{g} \mathrm{H} \mathrm{H}_{2} \mathrm{O}_{2}$ / mg catalyst per hour at $\mathrm{pH} 12$. This compares favorably with graphitic carbon nitride, with 0.7-0.8 $\mu \mathrm{g} \mathrm{H}_{2} \mathrm{O}_{2}$ / mg catalyst per hour at $\mathrm{pH}$ 7.,7 Meanwhile, P3HT is in most cases an efficient photosubstrate, with TON $\leq 1$. Rates of P3HT oxidation with simultaneous $\mathrm{H}_{2} \mathrm{O}_{2}$ evolution are rapid, for example at $\mathrm{pH} 7$ in "blank" conditions, P3HT produces the most peroxide of the three materials. The general observation of oxygen reduction to $\mathrm{H}_{2} \mathrm{O}_{2}$ should motivate future study into the exact mechanistic pathway(s) involved.

Table 1. Hydrogen peroxide concentrations in solutions of $\mathrm{pH} 2$, 7 , and 12 photogenerated by organic thin film illuminated over 20h on a solar simulator. Four different electron-donor conditions were used: $10 \mathrm{mM}$ of formate, oxalate, or phenol, or "blank" referring to water with added $\mathrm{HCl}$ or $\mathrm{NaOH}$ for adjusting $\mathrm{pH}$. Solution volume was $0.4 \mathrm{ml}$. $30 \mathrm{nmols}$ of organic semiconductor were used throughout.

\begin{tabular}{|c|c|c|c|c|}
\hline $\begin{array}{l}\text { Organic } \\
\text { semicon- } \\
\text { ductor and } \\
\mathrm{pH}\end{array}$ & $\begin{array}{l}{\left[\mathrm{H}_{2} \mathrm{O}_{2}\right], \mu \mathrm{M}} \\
\text { donor: } \mathrm{H}_{2} \mathrm{O} \\
\text { "blank" }\end{array}$ & $\begin{array}{l}{\left[\mathrm{H}_{2} \mathrm{O}_{2}\right]} \\
\mu \mathrm{M} \\
\text { donor: } \\
\text { formate }\end{array}$ & $\begin{array}{l}{\left[\mathrm{H}_{2} \mathrm{O}_{2}\right]} \\
\mu \mathrm{M} \\
\text { donor: } \\
\text { oxalate }\end{array}$ & $\begin{array}{l}{\left[\mathrm{H}_{2} \mathrm{O}_{2}\right],} \\
\mu \mathrm{M} \\
\text { donor: } \\
\text { phenol }\end{array}$ \\
\hline EPI, pH 2 & 0 & 74 & 231 & 915 \\
\hline EPI, pH 7 & 11 & 52 & 55 & 1019 \\
\hline EPI, pH 12 & 28 & 23 & 51 & 357 \\
\hline $\begin{array}{l}\text { PTCDI, pH } \\
2\end{array}$ & 0 & 0 & 3092 & 0 \\
\hline $\begin{array}{l}\text { PTCDI, pH } \\
7\end{array}$ & 31 & 30 & 2883 & 349 \\
\hline $\begin{array}{l}\text { PTCDI, pH } \\
12\end{array}$ & 54 & 92 & 0 & 97 \\
\hline $\begin{array}{l}\text { P3HT, } \mathrm{pH} \\
2\end{array}$ & 65 & 91 & 211 & 30 \\
\hline $\begin{array}{l}\text { P3HT, } \mathrm{pH} \\
7\end{array}$ & 99 & 56 & 64 & 44 \\
\hline $\begin{array}{l}\text { P3HT, pH } \\
12\end{array}$ & 73 & 29 & 75 & 48 \\
\hline
\end{tabular}

To confirm the hypothesis that a true photocatalytic cycle of oxygen reduction to peroxide with accompanying oxidation of the various donors exists, we fabricated semiconductor photoelectrodes and tested for photoanodic oxidation of donors in deoxygenated conditions (Figure 3a). We carried out chronoamperometry measurements with on/off dark and light conditions under argon, and found that both EPI (Figure 3b) and PTCDI (Figure 3c) give photoanodic currents in the presence of formate, oxalate, and phenol. PTCDI showed photoanodic current in blank electrolyte as well. By virtue of its deeper HOMO level, PTCDI is thermodynamically able to oxidize water to $\mathrm{O}_{2}$ and at higher $\mathrm{pH}$ the direct oxidation of water to $\mathrm{H}_{2} \mathrm{O}_{2}$ could be also possible. We tested if $\mathrm{H}_{2} \mathrm{O}_{2}$ was evolved via photooxidation by performing photoanodic chronoamperometry in deoxygenated conditions up to 5.5 hours, and were never able to detect any $\mathrm{H}_{2} \mathrm{O}_{2}$. This experiment further proves that $\mathrm{H}_{2} \mathrm{O}_{2}$ is a product exclusively of oxygen reduction. These results together confirm that indeed photoinduced holes in the valence band of the respective semiconductors are responsible for oxidation of the various donors. P3HT electrodes did not show any photoanodic currents under these conditions, attributable to the fact that P3HT exclusively supports hole mobility, and for the photoanodic process transport of electrons is required. 


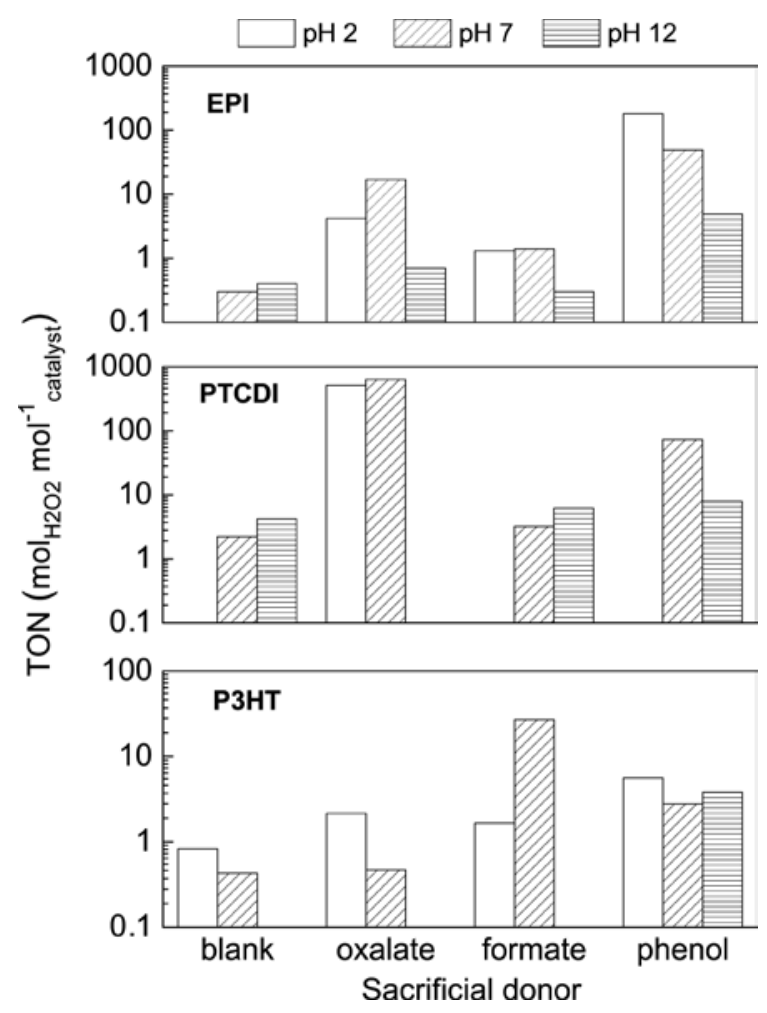

Figure 2. Hydrogen peroxide photogeneration efficiency in terms of turnover number. $10 \mathrm{mM}$ of sacrificial donor was used in all experiments, with $30 \mathrm{nmol}$ of the organic semiconductors. Results are not shown for conditions where no or trace amounts of $\mathrm{H}_{2} \mathrm{O}_{2}$ were detected.

a)

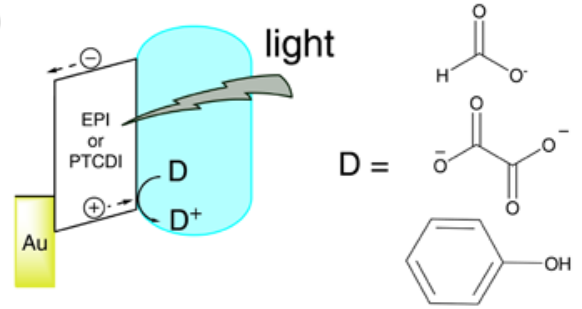

b)

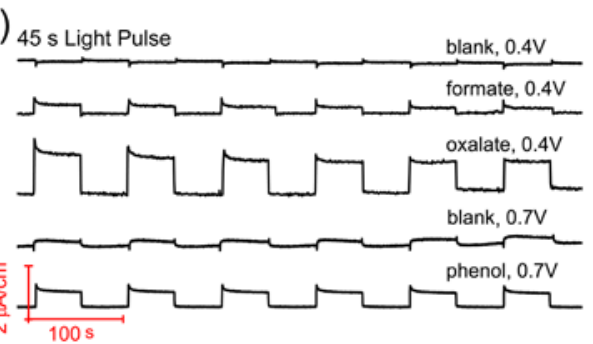

c)

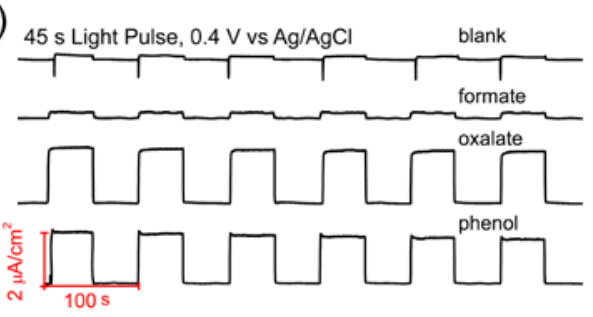

Figure 3. a) Photoanodic current experiment to verify the mechanism of photochemical oxidation performed by the organic semiconductors on electron donors formate, oxalate, phenol, or water. Chronoamperometry at 0.4 or $0.7 \mathrm{~V}$ (vs. AgAgCl reference) for a film of EPI (b) and PTCDI (c) on a gold electrode, demonstrating clear photoanodic oxidation of formate, oxalate, and phenol, and in the case of PTCDI, water. 
While heterogeneous thin films are appropriate for some practical devices, maximizing photocatalytic active area by creating colloidal nanoparticles is often employed for efficient photocatalysis. We therefore synthesized EPI nanocrystals with aqueous colloidal stability and tested their photocatalytic performance. EPI nanocrystals were synthesized by solubilizing deprotonated EPI molecules in DMSO/KOH and reprecipitation into water containing poly(vinylpyrrolidone) and sodium dodecyl sulfate as stabilizers (Figure 4a inset). Excess stabilizer was removed by dialysis of the nanoparticles. The resultant nanoparticles were evaluated by dynamic light scattering and showed stable size distribution (average $\approx 140 \mathrm{~nm}$ ) over one month, with some aggregation visible only after 2.5 months (Figure 4a). Optical absorption and photoluminescence also did not show changes over time (Figure 4b). Colloidal nanocrystals showed 2-4 times faster $\mathrm{H}_{2} \mathrm{O}_{2}$ evolution rate than equivalent amounts of thin-film EPI (Figure 4c-d), and better TONs at pH 2. At pH 2, the "blank" case gave a TON $>1$, which can be attributed to photochemical oxidation of the ligand poly(vinylpyrrolidone) $)^{29}$ as the sacrificial electron donor (Figure 4c). Phenol functioned as a good donor for EPI crystals, however TON was not calculated since the oxidation products of phenol have overlapping absorption with EPI, thus resulting in an overestimated TON. Overall these results are consistent with the interpretation that colloidal nanocrystals offer a higher exposed catalytic surface area.
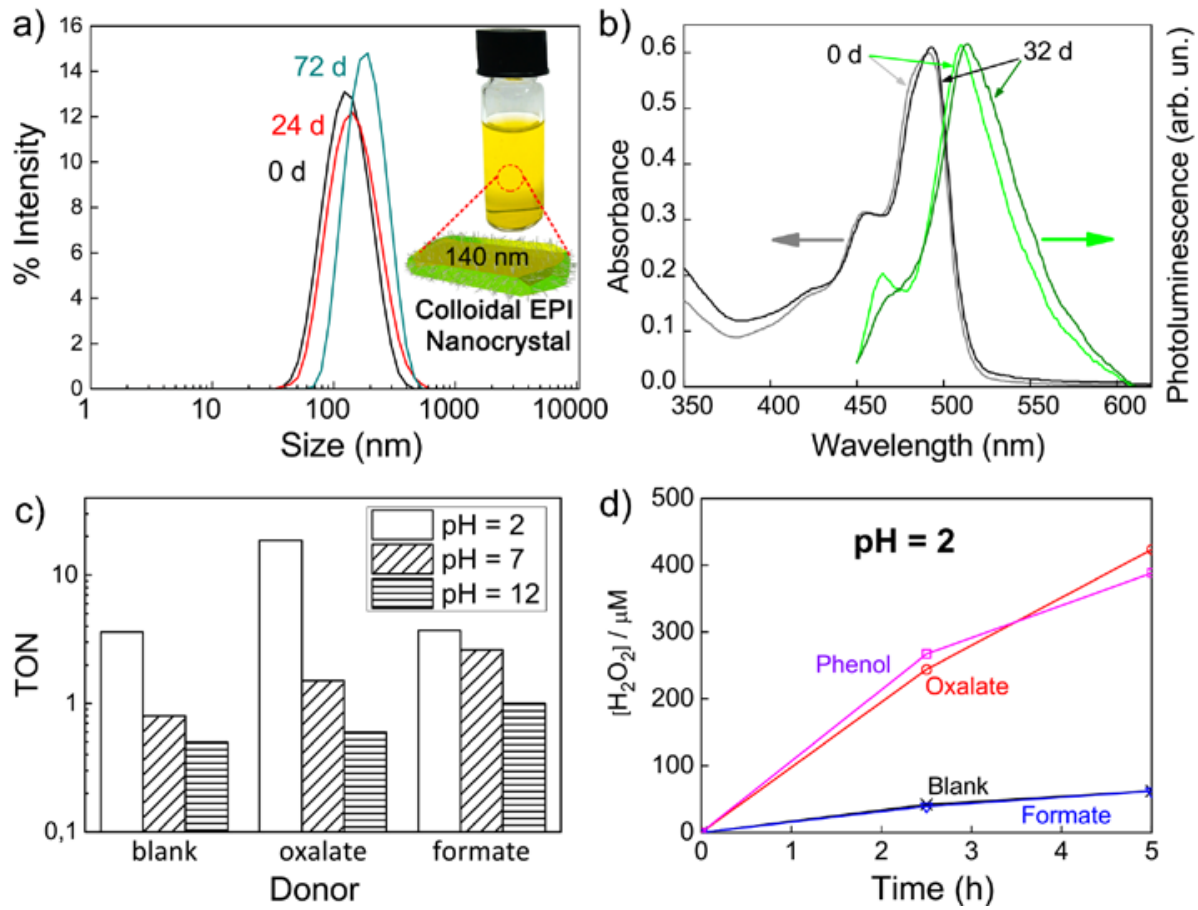

Figure 4. Epindolidione colloidal nanoparticles. a) inset shows schematic of colloidal EPI nanocrystals stabilized with sodium dodecyl sulfate and poly(vinylpyrrolidone); dynamic light scattering size distribution for EPI NCs measured over 72 days after initial synthesis, evidencing good colloidal stability. b) Optical absorption and photoluminescence measured for the same colloid. c) TON for $\mathrm{H}_{2} \mathrm{O}_{2}$ evolution with EPI colloids at $\mathrm{pH}$ 2, 7, and 12. d) $\mathrm{H}_{2} \mathrm{O}_{2}$ over time during irradiation under $\mathrm{pH} 2$ conditions.

In summary, we have found that three types of organic semiconductors have the ability to photochemically reduce oxygen to $\mathrm{H}_{2} \mathrm{O}_{2}$. Simultaneous photooxidation of various donors yields a true photocatalytic cycle, however this competes with self-oxidation of the organic semiconductor itself as the sacrificial electron donor. Materials with shallow HOMO levels such as P3HT produce $\mathrm{H}_{2} \mathrm{O}_{2}$ efficiently with essentially quantitative oxidation of the organic semiconductor. On the other hand, PTCDI, with its deep HOMO level, behaves like a true catalyst, and significantly, is capable of photooxidation of water. In addition, when colloidal nanocrystals can be obtained instead of thin films, as in the case of EPI, higher TONs can be achieved thanks to higher exposed catalytic surface. From the point of view of long-term stability of photocatalysts for $\mathrm{H}_{2} \mathrm{O}_{2}$ evolution, understanding and preventing of the oxidation process is an important consideration. Based on the trend that stability and TON apparently increase as the HOMO level becomes lower (PTCDI $<$ EPI $<$ P3HT) it is easy to conclude that the deeper the HOMO, the more stable the material will be as a photocatalyst. Further research is needed to understand the picture fully, as all materials evaluated here do degrade, even PTCDI with the deepest HOMO level. Substitution with electron withdrawing groups may be carried out not only to bring down HOMO levels, but to block sites of potential degradative reactivity. Quantum efficiency of the photocatalytic process remains below $1 \%$, largely limited by the low exciton separation efficiency in organic semiconductors. This invites the 
possibility of optimizing the process by making classic donor-acceptor heterojunctions and/or nanostructuring the semiconductor to maximize interface with the aqueous medium. For the field of photocatalysis in energy conversion applications, our results are encouraging in demonstrating intrinsic photocatalytic features of organic semiconductors, including oxidative water splitting, and should pave the way for further studies to achieve cheap and scalable semiconductor catalysts.

\section{ASSOCIATED CONTENT}

The Supporting Information is available free of charge on the ACS Publications website. Experimental methods are detailed in this document.

\section{AUTHOR INFORMATION}

\section{Corresponding Author}

*E-mail: eric.glowacki@liu.se

\section{ACKNOWLEDGMENT}

We acknowledge funding from the Wallenberg Center for Molecular Medicine at Linköping University for support of this work.

\section{REFERENCES}

(1) Chen, Z.; Dinh, H. N.; Miller, E. Photoelectrochemical Water Splitting Standards, Experimental Methods, and Protocols; Springer: New York, 2013.

(2) Hisatomi, T.; Kubota, J.; Domen, K. Recent Advances in Semiconductors for Photocatalytic and Photoelectrochemical Water Splitting. Chem. Soc. Rev. 2014, 43, 7520-7535.

(3) Habisreutinger, S. N.; Schmidt-Mende, L.; Stolarczyk, J. K. Photocatalytic Reduction of $\mathrm{CO}_{2}$ on $\mathrm{TiO}_{2}$ and Other Semiconductors. Angew. Chem. Int. Ed. Engl. 2013, 52, 7372-7408.

(4) Disselkamp, R. S. Can Aqueous Hydrogen Peroxide Be Used as a Stand-Alone Energy Source? Int. J. Hydrogen Energy 2010, 35, 1049-1053.

(5) Shiraishi, Y.; Kanazawa, S.; Kofuji, Y.; Sakamoto, H.; Ichikawa, S.; Tanaka, S.; Hirai, T. Sunlight-Driven Hydrogen Peroxide Production from Water and Molecular Oxygen by Metal-Free Photocatalysts. Angew. Chemie - Int. Ed. 2014, 53, 13454-13459.

(6) Fukuzumi, S. Artificial Photosynthesis for Production of Hydrogen Peroxide and Its Fuel Cells. Biochim. Biophys. Acta - Bioenerg. 2016, 1857, 604-611.

(7) Kofuji, Y.; Isobe, Y.; Shiraishi, Y.; Sakamoto, H.; Tanaka, S.; Ichikawa, S.; Hirai, T. Carbon Nitride-Aromatic Diimide-Graphene Nanohybrids: Metal-Free Photocatalysts for Solar-to-Hydrogen Peroxide Energy Conversion with 0.2\% Efficiency. J. Am. Chem. Soc. 2016, 138, 10019-10025.

(8) Lanzarini, E.; Antognazza, M. R.; Biso, M.; Ansaldo, A.; Laudato, L.; Bruno, P.; Metrangolo, P.; Resnati, G.; Ricci, D.; Lanzani, G. Polymer-Based Photocatalytic Hydrogen Generation. J. Phys. Chem. C 2012, 116, 10944-10949. 
(9) Ng, C. H.; Winther-Jensen, O.; Ohlin, C. A.; Winther-Jensen, B. Exploration and Optimisation of poly(2,2'Bithiophene) as a Stable Photo-Electrocatalyst for Hydrogen Production. J. Mater. Chem. A 2015, 3, $11358-11366$.

(10) Fumagalli, F.; Bellani, S.; Schreier, M.; Leonardi, S.; Rojas, H.; Ghadirzadeh, A.; Tullii, G.; Savoini, A.; Marra, G.; Meda, L.; Gratzel, M.; Lanzani, G.; Mayer, M.; Antognazza, M.; Di Fonzo, F. Hybrid Organic-Inorganic $\mathrm{H}_{2}$-Evolving Photocathodes: Understanding the Route towards High Performances Organic Photoelectrochemical Water Splitting. J. Mater. Chem. A 2016, 4, 2178-2187.

(11) Zhang, G.; Lan, Z.-A.; Wang, X. Organic Conjugated Semiconductors for Photocatalytic Hydrogen Evolution with Visible Light. Angew. Chemie Int. Ed. 2016, 55, 15712-15727.

(12) Lai, L.-H.; Gomulya, W.; Berghuis, M.; Protesescu, L.; Detz, R. J.; Reek, J. N. H.; Kovalenko, M. V.; Loi, M. A. Organic-Inorganic Hybrid Solution-Processed $\mathrm{H}_{2}$-Evolving Photocathodes. ACS Appl. Mater. Interfaces 2015, 7, 19083-19090.

(13) Bornoz, P.; Prévot, M. S.; Yu, X.; Guijarro, N.; Sivula, K. Direct Light-Driven Water Oxidation by a Ladder-Type Conjugated Polymer Photoanode. J. Am. Chem. Soc. 2015, 137, 15338-15341.

(14) Suppes, G. M.; Fortin, P. J.; Holdcroft, S. Photoelectrochemical Hydrogen Evolution: Single-Layer, Conjugated Polymer Films Bearing Surface-Deposited Pt Nanoparticles. J. Electrochem. Soc. 2015, 162, H551-H556.

(15) Rojas, H. C.; Bellani, S.; Sarduy, E. A.; Fumagalli, F.; Mayer, M. T.; Schreier, M.; Gra, M.; Fonzo, F. Di; Antognazza, M. R. All Solution-Processed, Hybrid Organic - Inorganic Photocathode for Hydrogen Evolution. ACS Omega 2017, 2, 3424-3431.

(16) Bellani, S.; Fazzi, D.; Bruno, P.; Giussani, E.; Canesi, E. V.; Lanzani, G.; Antognazza, M. R. Reversible P3HT/oxygen Charge Transfer Complex Identification in Thin Films Exposed to Direct Contact with Water. J. Phys. Chem. C 2014, 118, 6291-6299.

(17) Tortiglione, C.; Antognazza, M. R.; Tino, A.; Bossio, C.; Marchesano, V.; Bauduin, A.; Zangoli, M.; Morata, S. V.; Lanzani, G. Semiconducting Polymers Are Light Nanotransducers in Eyeless Animals. Sci. Adv. 2017, 3, e1601699.

(18) Zangoli, M.; Di Maria, F.; Zucchetti, E.; Bossio, C.; Antognazza, M. R.; Lanzani, G.; Mazzaro, R.; Corticelli, F.; Baroncini, M.; Barbarella, G. Engineering Thiophene-Based Nanoparticles to Induce Photodransduction in Live Cells under Illumination. Nanoscale 2017, 9, 9202-9209.

(19) Liu, D.; Wang, J.; Bai, X.; Zong, R.; Zhu, Y. Self-Assembled PDINH Supramolecular System for Photocatalysis under Visible Light. Adv. Mater. 2016, 28, 7284-7290.

(20) Jakešová, M.; Apaydin, D. H.; Sytnyk, M.; Oppelt, K.; Heiss, W.; Sariciftci, N. S.; Głowacki, E. D. Hydrogen-Bonded 
Organic Semiconductors as Stable Photoelectrocatalysts for Efficient Hydrogen Peroxide Photosynthesis. Adv. Funct. Mater. 2016, 26, 5248-5254.

(21) Węcławski, M. K.; Jakešová, M.; Charyton, M.; Demitri, N.; Koszarna, B.; Oppelt, K.; Sariciftci, S.; Gryko, D. T.; Głowacki, E. D. Biscoumarin-Containing Acenes as Stable Organic Semiconductors for Photocatalytic Oxygen Reduction to Hydrogen Peroxide. J. Mater. Chem. A 2017, 5, 20780-20788.

(22) Warczak, M.; Gryszel, M.; Jakešová, M.; Đerek, V.; Głowacki, E. D. Organic Semiconductor Perylenetetracarboxylic Diimide (PTCDI) Electrodes for Electrocatalytic Reduction of Oxygen to Hydrogen Peroxide. Chem. Commun. 2018, 54, 1960-1963.

(23) Głowacki, E. D.; Romanazzi, G.; Yumusak, C.; Coskun, H.; Monkowius, U.; Voss, G.; Burian, M.; Lechner, R. T.; Demitri, N.; Redhammer, G. J.; Sünger, N.; Suranna, G. P.; Sariciftci, S. Epindolidiones-Versatile and Stable Hydrogen-Bonded Pigments for Organic Field-Effect Transistors and Light-Emitting Diodes. Adv. Funct. Mater. 2015, 25, 776-787.

(24) Głowacki, E. D.; Tangorra, R. R.; Coskun, H.; Farka, D.; Operamolla, A.; Kanbur, Y.; Milano, F.; Giotta, L.; Farinola, G. M.; Sariciftci, N. S. Bioconjugation of Hydrogen-Bonded Organic Semiconductors with Functional Proteins. J. Mater. Chem. C 2015, 3, 6554-6564.

(25) Zhan, X.; Facchetti, A.; Barlow, S.; Marks, T. J.; Ratner, M. A.; Wasielewski, M. R.; Marder, S. R. Rylene and Related Diimides for Organic Electronics. Adv. Mater. 2011, 23, 268-284.

(26) Günes, S.; Neugebauer, H.; Sariciftci, N. S. Conjugated Polymer-Based Organic Solar Cells. Chem. Rev. 2007, 107, 1324-1338

(27) Simon, D. T.; Gabrielsson, E. O.; Tybrandt, K.; Berggren, M. Organic Bioelectronics: Bridging the Signaling Gap between Biology and Technology. Chem. Rev. 2016, 116, 13009-13041.

(28) Josephy, P. D.; Eling, T.; Mason, R. P. The Horseradish Peroxidase-Catalyzed Oxidation of 3,5,3',5’tetramethylbenzidine. Free Radical and Charge-Transfer Complex Intermediates. J. Biol. Chem. 1982, 257, 36693675.

(29) Suave, J.; José, H. J.; Fatima, R. De; Muniz, P. Photocatalytic Degradation of Polyvinylpyrrolidone in Aqueous Solution Using $\mathrm{TiO}_{2} / \mathrm{H}_{2} \mathrm{O}_{2}$ / UV System. Environ. Technol. 2017, doi.org/10.1080/09593330.2017.1330365. 
Organic semiconductors can photochemically reduce oxygen to hydrogen peroxide, in the process oxidizing themselves; or a given sacrificial electron donor, creating a photocatalytic cycle. If the highest-occupied molecular orbital of the semiconductor is below the oxidation potential of water, water can be photooxidized, leading to oxidative water splitting with accompanying peroxide evolution.

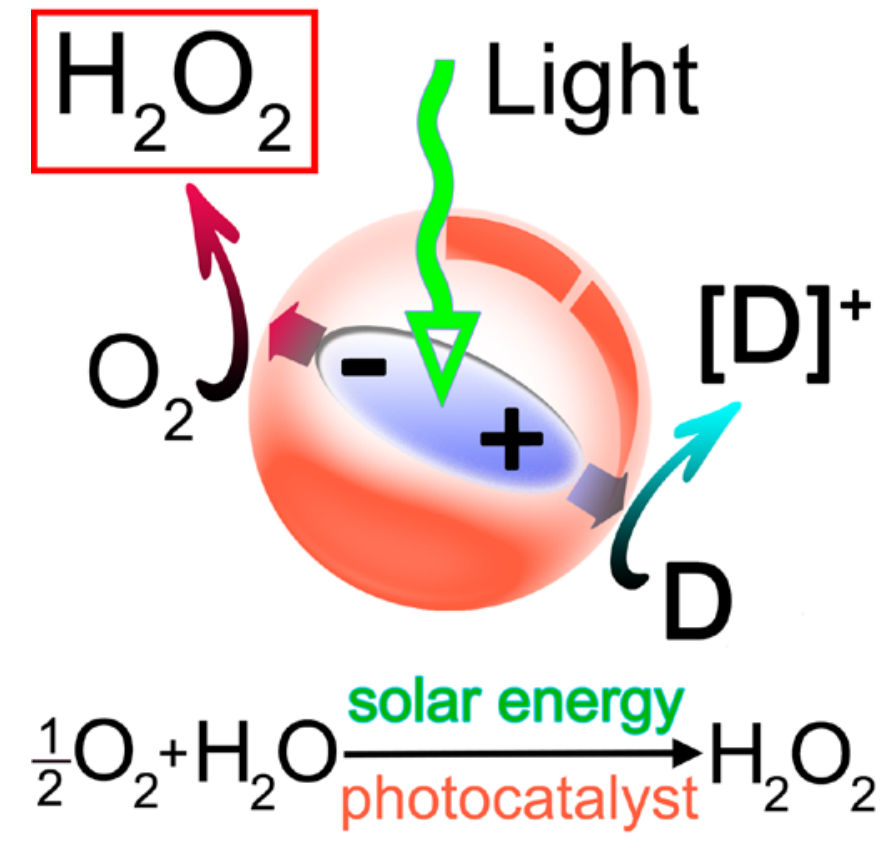

